\title{
MODELLING OF NET FLOWS TO INVESTMENT FUNDS
}

\author{
Leonas Simanauskas ${ }^{1}$, Aleksandras Vytautas Rutkauskas², Irena Kucko ${ }^{3}$ \\ Vilnius Gediminas Technical University, \\ Saulètekio al. 11, LT-2040 Vilnius, Lithuania. \\ E-mail: ${ }^{1}$ leonas.simanauskas@ef.vu.lt; \\ ${ }^{2}$ ar@vv.vtu.lt; \\ 3 irena.kucko@vv.vtu.lt \\ Received: 7 February, 2003
}

\begin{abstract}
The paper presents the general model of net flows to investment funds, which helps to analyse the flows and to solve the problem structurally. The model includes various investment guidelines and different fund types, aspects of risk influence are discussed separately. Furthermore, the conception and techniques of integrated assets and liabilities portfolio management are applied forming and managing the portfolio of investment fund. Integrated assets and liabilities management is based on computerised decision models that represent both the assets and liabilities associated with the business line, characterise the uncertainty of the future environment and produce strategies for structuring the assets and liabilities in business ways that are profitable across a range of alternative future environments. The methods of imitative modelling are used and obtained results are presented in geometrical form of portfolio sets, their efficiency zones, density and survival functions.
\end{abstract}

Keywords: investment analysis, investment funds, net assets value, integrated assets and liabilities portfolio, efficiency zone.

\section{Introduction}

Questions of which stock or bond to select, when to buy and when to sell have plagued investors for as long as there have been organised capital markets. Such concerns lie at the very heart of the investment fund concept and in large part explain the growth that investment funds have experienced. Many investors lack the time, know-how, or commitment to manage their own portfolios, so they turn to professional fund managers and simply let them decide which securities to buy and when to sell.

The benefits of investment funds, where individuals from all walks of life pool their savings together, can be summed up as offering everybody - from professional or institutional investors to people with limited time, or limited investment skills or modest means access to investment returns otherwise only available to more sophisticated investors, who are able to buy their own professional portfolio management advice.

The research object of this paper is one of the elements of a financial system, which belongs to the so- called other popular or alternative investment instruments - an investment fund. Basically, we analyse a type of financial services organisation that receives money from its shareholders and then invests those funds on their behalf in a diversified portfolio of securities. An investment in an investment fund really represents an ownership position in a professionally managed portfolio of securities $[1,4]$.

Abundance of investment funds types and variety of structures can mislead even experienced investor. Historical development have determined different preferences for savings in different countries with their legal and finance systems, that's why different investment habits and structures have been formed in different countries throughout the time. Lately, in conditions of globalisation, other tendencies are observed: the structures of the funds, investment politics, state regulation system speeds up the assimilation of these institutions. International organisations pass legal acts, harmonising norms and procedures of different countries, legislators make possibility for funds of different forms to operate in one finance and legal space. 
Thus, seeking to satisfy the needs of investors, the founding of funds, which would operate not in one country, is induced.

Given below model is created on the base of investment fund definition and one of the possible classifications, it helps to understand the interrelation as well as the incoming and outgoing flows.

\section{The model of net flows to investment funds}

Investment funds can be classified according to their investment objectives, as it is shown in figure 1. The upper part of figure represents the essence of investment fund definition and explains the movement of net flows as well. An investment fund is an intermediary between investors and the market. It pools the capital paid in by many individual investors and invests it according to defined investment guidelines in specific markets and assets.

An investment fund or collective investment scheme is a financial investment vehicle, which is aimed at private investors - little or large - or institutional investors - insurance companies, banks - and offers the following five key advantages over direct investment in shares, bonds, and property:

- Risk is spread and therefore reduced;
- Funds allow you to tap into professional, expert and full time investment management expertise;

- Funds are cost effective;

- Funds offer access to markets that may otherwise be closed or too technical for retail/individual investors;

- Funds benefit from institutional safety, which means they are heavily regulated and supervised.

The following definitions give a description of the four main categories of investment funds, which can each have their specific investment objectives:

Money market funds invest a sizeable portion of the fund's portfolio in short term bonds and/or money market instruments (such as certificates of deposit, commercial paper, treasury bills, and so on) and/or cash (cash accounts, saving accounts, term deposits, and so on). The fund's average maturity usually does not exceed one year and therefore a money market fund is less vulnerable to interest rate fluctuations, whilst credit risk is expected to be negligible. Within this category a further distinction can be made following the currency exposure of the fund: funds invested in US\$-denominated instruments, invested in $€$-denominated instruments, and so on. In principle investment funds are available for all major currencies.

Bond funds invest in fixed interest rate securities as a sizeable portion of the fund's portfolio. An important

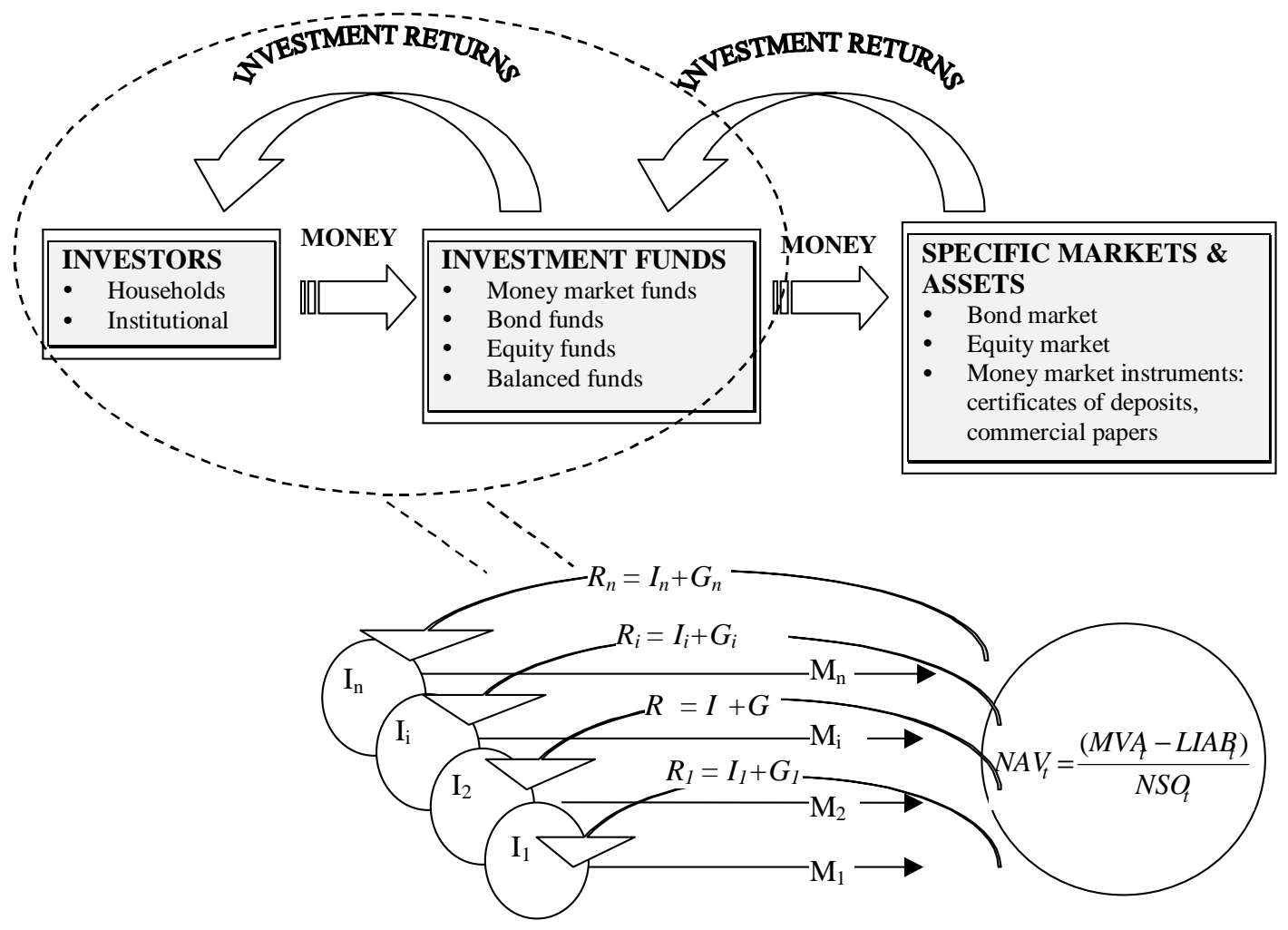

Fig. 1. Net flows to investment funds 
distinction is that individual bonds have final maturity dates, whereas bond funds do not (short-, medium-, and long-term funds), nor is the income bond funds pay out fixed like with individual bonds. Please note that when interest rates rise, the value of your bond fund generally drops. Bond funds generally have a global average maturity of more than one year and its investments can consist of different instruments with very different quality ratings. As a result some bond funds can experience higher volatility and credit risk can vary widely, depending on whether you choose gilt-edge government bonds (high grade quality rating) or high-yield corporate bonds (e.g. one minute dot.coms). Currency risk enters the equation in the event of a multi-bond fund. Within this category a further distinction can be made according to the currency or credit exposure, such as single or multiple currency funds as well as bonds with a different credit exposure.

Equity funds invest in the stock market at a significant portion of the fund's portfolio. Equity funds are frequently also called stock funds. They always reflect the characteristics of the market (i.e. market risk). Within this category a further distinction can be made following the chosen exposure:

- Global,

- Regional (e.g. Eurozone),

- Country,

- Sector (e.g. pharmaceutical, telecoms), or

- Theme (e.g. ethical fund, ecological fund, emerging markets).

Balanced funds (also called Asset Allocation Funds or Mixed Funds) spread their portfolio over the three main asset classes described above (money market instruments, bonds and equities). Within balanced funds a further distinction can be made following the percentage they allocate to each of these 3 different asset classes. The more these funds invest in money market instruments and fixed income instruments (bonds), the less risk they bear, the more equity exposure they have, the higher the risk profile of the fund becomes.

Investor's net flows, incoming to investment funds, are modelled at the bottom part of the figure. Here, $I_{1}, I_{2}$, $I_{i}, I_{n}$ are certain investors, $M_{1}, M_{2}, M_{i}, M_{n}$ are incoming money flows corresponding to these investors. $R_{1}$, $R_{2}, R_{i}, R_{n}$ are investment returns, outgoing from investment funds to many individual investors. Investment returns at time $\left(R_{t}\right)$ are calculated as sum of income $\left(I_{t}\right)$ at time and capital gain distribution at time $\left(G_{t}\right)$ :

$$
R_{t}=I_{t}+G_{t}
$$

The NAV (net asset value) must reflect the current market value of the fund's securities, as long as market quotations for those securities are readily available. Other assets are priced at fair value, determined in good faith by a fund's board of directors. The Investment Company Act of 1940 requires "forward pricing": shareholders purchasing or redeeming shares receive the next computed share price following the fund's receipt of the transaction order. Any income and expenses (including any fees) must be accrued through the date the share price is calculated. Changes in holdings and in the number of shares must be reflected no later than the first calculation of the share price on the next business day. Funds typically value exchangetraded securities using the closing prices from the exchange on which the securities are principally traded, even if the exchange closes before the fund's daily pricing time (which occurs with many foreign securities). If a material event that will likely affect the value of a security occurs after the exchange closed and before the fund's share price is determined, it may be necessary to determine the fair value of the security in light of that event.

$$
N A V_{t}=\frac{\left(M V A_{t}-L I A B_{t}\right)}{N S O_{t}},
$$

where $N A V_{t}$ is an investment fund's net asset value, $M V A_{t}$ is the market value of investment fund's assets, $L I A B_{t}$ is the value of investment fund's liabilities, $\mathrm{NSO}_{t}$ is the number of shares [16].

$$
r_{t}=\frac{\left(N A V_{t}-N A V_{t-1}\right)+I_{t}+G_{t}}{N A V_{t-1}},
$$

where $r_{t}$ - returns at time $t, I_{t}$ - income, $G_{t}$ - capital gain distribution at time [16].

Described situation can be illustrated by simple example: if at the beginning of month t $N A V$ were $€ 10$, income and capital gain were accordingly $€ 0,05$ and $€ 0,04$. At the end of month net asset value made up $€ 10,03$. Then performance calculating returns:

$$
r_{t}=\frac{(10,03-10,00)+0,05+0,04}{10,00}=1,2 \% \text {. }
$$

It should be noted that this calculation of returns could be used to evaluate the efficiency of portfolio manager, it reveals the manager's investment decision results, but not always investor's gain. The latter is being dependent on the load charge. If investors paid 
$€ 10,50$ for one share at the end of month, including $€ 0,50$ the load charge, then $N A V_{t-1}$ are $€ 10,50$, not $€ 10,00$.

$$
r_{t}=\frac{(10,03-10,50)+0,05+0,04}{10,50}=-3,62 \% .
$$

If at the beginning of the month investor paid $€ 0,50$ load charge for one share, the profitability for him is $-3,62 \%$. But portfolio manager invested only $€ 10,00$ and the load went to intermediaries. Accordingly the activity of portfolio manager should be evaluated due to received returns from investment activity.

\section{Aspects of risk influence}

Life always has risks attached, there is no such thing as a risk-free investment as there is no right or wrong level of risk. What is appropriate for one person depends on their unique financial circumstances and objectives. A retired person is unlikely to take the same risks as a young person with no dependants. Some people are prepared to accept a greater degree of risk in the short term, as there may be significantly better rewards in the longer term.

Although, there is no need to explain that investment returns at time $\left(R_{t}\right)$ on their side influence incoming flows to investment funds $\left(M_{i}\right)$. Two aspects are distinguished: first, the standpoint of individual investor to risk, and then, the risk the investment fund collides with. The main groups of risk factors are discussed and the reason and source of certain kind of risk is analysed [5, 8].

Concentration of investments in a single type of asset can greatly increase your exposure to different types of risk. These risks can be reduced by spreading savings among a mix of funds invested in different types of assets. Risk can be further managed by choosing funds that match individual financial goals and by staying invested through periods of wide price swings. There is always a risk of losing money if when you want to cash in your holding at the same time as capital market prices are falling. This reinforces the importance of regular portfolio reviews to make sure it still meets your financial requirements.

Risk - a fundamental concept in investment theory and practice - in portfolio theory is described as the level of investment change and is calculated as a standard deviation of the market price [2]. It is associated with unfavourable economic consequences and the probability of loss. But this is unilateral view, because if risk were only associated with negative results, the investor's preparedness to invest and risk would be incomprehensible. A more precise definition would be if we said that risk is synonymous with uncertainty. Uncertainty is not always negative in finance: beside the possibility of experiencing results that are worse than expected, there is also the probability of getting even better results than expected. Sometimes risk is not only linked to the probability of loss, but also includes other indications, for instance, the connection between risk and aim, in other words, possible losses, when a set aim isn't attained [4]. But probably the most precise definition of risk in connection with securities investments would be: the deviation of the securities' profitability from the expected result. It is clear from definition that two variables describe the risk: the possibility of a deviation from expected results and the probability of this deviation.

The development of modern portfolio theory (MPT) over the last thirty years has helped us to understand the nature of risk and profit. Mathematical calculations can be incomprehensible to most individual investors, but the general conclusions of MPT are simple enough. The main principles $[2,12]$ :

- Each security has a specific risk, which depends on the activity of the issuer, its position in the market and the competence of the head. This risk isn't directly related to its position on the market but together with systemic risk, characteristic to the whole market, it is part of the risk of investing in securities.

- Risk in relation to the management of securities depends on the number of securities. The risk for a portfolio consisting of one type of securities decreases considerably when the number of types of securities is increased up to 25 . As it can be seen in figure 2, the systemic risk was 7,085 on the New York Stock Exchange, while the risk for one security made up 46,619. Specific risk decreases when the number of securities increases in portfolio. The speed of risk change is very

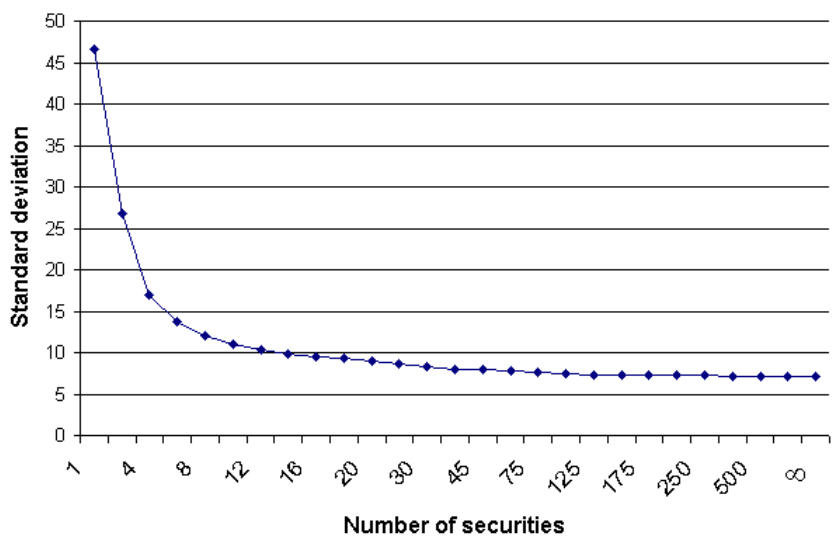

Fig. 2. Specific and systemic risk 
large for the first twelve securities. It should be noted that according to chosen investment instrument (stock, bond, bill and other) the structure of systemic risk could be different.

The first factor is rather difficult to understand. It is related to the mathematical analysis of profitability change over time. Anyway, investors perceive shortly afterwards, that securities with a high specific risk often don't attain their expected profitability. Only a beginner can naively believe that securities with a very high risk will give a high profit. Actually, the risk on a profit unit of a small portfolio of risky securities is higher than the risk on a larger portfolio. The past experience of investors from developed countries, where there are no longer any illusions about high risk and high profit investments, has resulted in the growth of investments to investment funds. Investment funds, owing to their high levels of diversification, considerably decrease or even abolish the specific risk attached to securities investments.

Research has shown that the second factor is important because investors seek to decrease the risk more often than to increase the profit.

The main reason for the success of investment funds in USA and Western Europe lies in diversification. The greater meaning this factor has in developing countries, where the specific risk of securities is usually higher, thus the diversification gives a greater advantage.

Taking into consideration, that investors don't tolerate risk, investments with high systemic risk have distinguished themselves with high expected profitability; and analogically, investments with low systemic risk will have a low expected rate of return. It's possible that an investment with a rather high level of general risk will have relatively low expected profitability because of the relatively low proportion of systemic risk. On the contrary, investments with low general risk will have a rather high expected rate of return because the systemic risk forms the greatest part of the risk.

It is useful to analyse the cause and source of systemic and specific risk. Risk is related to fluctuations of expected income, which is closely connected to stock changes in market price and dividend payments. Thus, risk-causing factors are the same factors that cause stock price changes or influence the level of paid dividends.

It is an important part of decision theory, that's why a general precondition can be made, that the main influence on stock price change and the level of paid dividend has the change of enterprise's money flows. Consequently, the conclusion can be made that the risk of investing in the stocks of a certain company is related to changes in its money flows. The greater uncertainty over the company's money flows the greater the risk the investor faces when choosing the stocks of that company.

Many factors influence the expected money flows of a company - management quality and employer-employee relations, the efficiency of its advertising campaigns and any scientific research performed by the company. More general factors include the rate of the sector's economic growth, the level of aggregate demand, changes in currency exchange rates, taxes, interest rates and so on.

There are two main groups of factors. Factors specific to the certain enterprise (e.g., scientific research), and factors that influence all enterprises in a particular economy (e.g., aggregate demand). The latter are the market or systemic risk factors, and the former, that influence only one specific enterprise, are specific risk factors.

The impact of factors that influence only one company can be diluted if the portfolio includes many shares of different companies. That is why it can be said that the impact of these factors is negligible and practically ignored in the market portfolio. This cannot be said about general economical factors that influence any company in a particular economy. That's why the group of general factors remains and has an analogical impact that can't be avoided.

The fixed and variable costs ratio is very important to the companies whose expected money flows strongly depend on various macroeconomic factors. The large proportion of fixed costs is the additional source of risk for the companies, which already collide with considerable systemic risk. When a company's turnover decreases and its fixed costs do not change, the company can find itself in an unenviable situation. If the company, those incomes are sensitive to macroeconomic changes, has a low ratio of fixed and variable costs, then it can decrease the high systemic risk. If the company's expected incomes are insensitive or less sensitive to macroeconomic changes, it can't manage costs much, because in this case the costs ratio neither improves nor worsens the situation. Taking into consideration that investors seek to avoid additional risk, companies whose expected incomes are very sensitive to macroeconomics changes should be concerned that the ratio of fixed and variable costs is as favourable as possible and assists in decreasing the rather high level of risk. 


\section{Integrated assets and liabilities portfolio theory application to investment funds}

The definition of an investment fund already characterises the main aspect of its activity - security portfolio management. An investment fund portfolio is a set of different types of assets, formed on the basis of asset types and set proportional usage, seeking for the return. The simplest way to describe the portfolio is to indicate its structure, i.e. to indicate one or another type of asset and the amount of it in the portfolio.

Portfolio theory is dedicated to solve the main problem each investor is faced with - how to invest capital and gain maximal return with minimal risk [3]. Under the term of portfolio we are not thinking about an investment set in general, but about a structural collection, which reconciles investment portfolio possibilities with investment fund's need for a return with risk management possibilities. Moreover, it isn't enough to know one informative possibility for investor; one should know all possibilities, i.e. the entire distribution of possibilities under a certain risk level $[13,14,15]$.

Formation and management of a portfolio requires an operational evaluation and description of various possible portfolio conditions (also available on the efficient line) as well as the analysis of other characteristics. Portfolio decisions must be made while it is not possible to describe separate assets, thus a portfolio's return possibilities, with a single explanation, but with their probability distribution. Therefore average return isn't the most suitable indicator for determining the condition of a certain portfolio. Average profitability is the general condition of profit possibilities; still it is only the one of possibilities, while investor may be interested in the quartile of a certain level or other characteristics.

This century is often regarded as the age of risk and uncertainty. Among financial intermediaries this perspective was called as integrated asset and liability management (IALM) perspective. IALM is based on computerised decision models that represent both the assets and liabilities associated with the business line, characterise the uncertainty of the future environment and produce strategies for structuring the assets and liabilities in business ways that are profitable across a range of alternative future environments. Because of a complex volatility of the future there is no alternative to IALM for financial intermediaries. The conception and techniques of integrated assets and liabilities portfolio management are attempted to apply to investment funds in this part of the paper $[6,9]$.
It is often supposed that management for investment fund is nothing more than determining of correct structure of assets and liabilities. It seems to be truth if one could define this structure under stochastic behaviour of main properties of assets and liabilities. The structure of assets and liabilities of an investment fund must guarantee the realisation of the fund's aims, that is, the growth of net assets value. In other words, the portfolio of assets and liabilities must guarantee a desirable return considering risk management possibilities.

In many modern manuals a geometric portfolio view is analysed by putting investment return as a random variable means on ordinate axis and their average standard deviation on the abscissa axis $[3,4,8]$. This approach will also be used when analysing integrated portfolio, but not only the means of random variables will be shown on the ordinate axis, but also other functions of these possible variables (minimum, maximum, quartile, median).

Integrated assets and liabilities portfolio (IALP) helps to reinforce integrated assets and liabilities management system (IALMS) as strategic decision making system. The main decision points over which IALP is integrated into IALMS are: where and how much to invest where and how much to borrow, how to use leverage, how to maximise corporation or individual wealth at each stage, how to make adequate decision under the risk and uncertainty.

On the other hand, IALP is used for financial forecasting system when the main financial statements: balance sheet, income statement, cash flow statement etc. are being generated [15]. IALP techniques are based entirely on stochastic modelling, so the principles of integrated risk management could be implemented into IALMS. That's why IALP could be helpful overcoming uncertainty and complexity of many financial management problems.

IALP as the system of mathematical model is presented in discrete form where the time period $\mathrm{T}$ also is divided by time moments: $t_{0}, t_{1}, \ldots, t_{n}$ into static intervals or stages $\left[\left(t_{0}, t_{1}\right),\left(t_{1}, t_{2}\right), \ldots,\left(t_{n-1}, t_{n}\right)\right]$.

For convenience of exposition we suppose that the stage coincide with one year period. The IALP switches on at start of each forecasting (planning) stage rendering changes to the asset and liability position, evaluating the results over the coming stage. Rebalancing assets and liabilities at times between reviewed point is not allowed. The mechanism of rebalancing depends on planning strategy is that stage by stage strategy or we have an integrated by stages (over time) strategy. In the case we use the stage by 
stage strategy. This situation simplifies exposition of portfolio techniques. There would be presented IALP as decision instrument on separate of all time period $\mathrm{T}$ though the behaviour of the managed system reacts on the issue of this decision and, vice versa, the objectives of the system cause the objectives and constraints of decision on separate stage.

Different behaviour of the system means different changes in balance sheet, different incomes, cash flow etc. statement results. Only core changes would be presented that happen throughout one stage as static ring of all chain: changes in wealth, structure of asset and liability as well as changes in microenvironment (price, risk etc.).

Relevant sets, accounting and decision variables, inputs, identities and governing equations would be defined for the IALP. Change in amount of every asset and liability would be treated as consisting of two nonintersecting components for analytical convenience. First component appears as a result of rebalancing of already existing amount of assets and liabilities. The total amount of asset and liability doesn't change in this component. The second component is an increase in every kind of asset and liability as a result of increase of total amount. Consequently those components are called: first - changes as result of rebalancing, second - newly introduced growth.

Let us define the following sets:

$t_{1}, t_{2}, \ldots, t_{n}$ - discrete times at which the IALP will be rebalanced.

$T$ - time horizon (period) consisting of $n:\left[\left(t_{0}, t_{1}\right)\right.$, $\left.\left[t_{1}, t_{2}\right), \ldots,\left(t_{n-1}, t_{k}\right)\right]$ intervals, $t_{k}=T$. Further time moment $(t+1)$ will be identified with $t_{k+1}$ if $t=t_{k}$.

$i$ - asset categories, $i=1,2, \ldots, n ; n$ - number of assets.

$j$ - liability categories, $j=1,2, \ldots, m ; m$ - number of liabilities.

$a_{t}^{i}$ - amount of $\mathrm{i}$ assets (in money) at time $t ; t=t_{1}, t_{2}$, $\ldots, t_{n}$.

$l_{t}^{j}$ - amount of $\mathrm{j}$ liability at time $t$.

Define the following decision and accounting variables:

$I_{t}^{a_{i}}$ - growth index of $i$ asset in result of rebalancing at the moment $t$.

$$
I_{t}^{a_{i}}=\left(1+\lambda_{t}^{a_{i}}\right)
$$

where $\lambda_{t}^{a_{i}}$ - change rate of $\mathrm{i}$ asset at the moment $t$. $I_{t}^{l_{j}}$ - growth index of $\mathrm{j}$ liability in result of rebalancing at the moment $\mathrm{t}$.

$$
I_{t}^{l_{j}}=\left(1+\lambda_{t}^{l_{j}}\right)
$$

where $\lambda_{t}^{l_{j}}$-change rate of $\mathrm{j}$ liability at the moment $t$.

$\lambda_{t, n}^{a_{i}}$ - fraction of assets newly invested in asset category $i$ at time $t_{i}$ or at the beginning of interval $[t,(t+1)] ; \sum \lambda_{t, n}=1, \lambda_{t, n} \geq 0$

$\bar{\lambda}_{t, n}^{a_{i}}$ - fraction of amount of "old" assets in newly invested $i$ asset.

$$
\bar{\lambda}_{t, n}^{a_{i}}=\lambda_{t, n}^{a_{i}} \times \lambda_{n},
$$

where $\lambda_{n}$ - growth rate of asset at time $t$.

$\overline{\overline{a_{t}^{i}}}$ - amount of $i$ assets after rebalancing and introducing new at moment $t$.

$$
\overline{\overline{a_{t}^{i}}}=a_{t}^{i}\left(1+\lambda_{t}^{r}+\bar{\lambda}_{t, n}\right),
$$

$\lambda_{t, n}^{l_{j}}$ - fraction of newly borrowed liabilities in liability category $j$ at time $t_{i}$, or at the beginning of interval $(t, t+1)$;

$\bar{\lambda}_{t, n}^{l_{j}}$ - fraction of amount of "old" liabilities in newly borrowed $j$ liability.

$$
\bar{\lambda}_{t, n}^{l_{j}}=\lambda_{t, n}^{l_{j}} \times \lambda_{t+1},
$$

where $\lambda_{t+1}-$ growth rate liability at moment $t$.

$P_{t+1}^{a i}-$ index of $i$ asset's price change in year $(t+1)$;

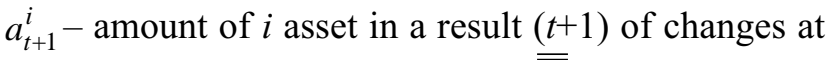
moment $t$ and price change $a_{t+1}^{i}=\overline{\overline{a_{t}^{i}}} \mathrm{P}_{t+1}^{a_{i}}$

$\Delta_{t+1}^{a i}$ - change in amount of i asset in the year $(t+1)$ because of price and increase in amount at moment $t$.

$$
\begin{gathered}
\Delta_{t+1}^{a i}=a_{t+1}^{i}-a_{t}^{i}, \\
a_{t+1}^{i}=a_{t}^{i}\left(1+\lambda_{t}^{a_{i}}+\overline{\lambda_{t, n}^{a_{i}}}\right) \times P_{t+1}^{a_{i}},
\end{gathered}
$$




$$
a_{t+1}^{i}=a_{t}^{i}\left(1+\lambda_{t}^{a_{i}}+\overline{\lambda_{t, n}^{a_{i}}}\right) \times\left(1+P_{t+1}^{a_{i}}\right),
$$

where $\Delta P_{t+1}^{a i}-$ price rate of $i$ asset.

$\Delta_{t+1, w}^{a i}$ - changes in wealth generated by $i$ asset. It consist of changes in amount of asset $i$ because of price changes by adding interest earned by asset $i$ and subs trending some transaction cost if some amount asset was sold.

$$
\Delta_{t+1, w}^{a i}=a_{t}^{i}\left(1+\lambda_{t}^{a_{i}}+\overline{\lambda_{t, n}^{a_{i}}}\right) \times\left(\Delta P_{t+1}^{a_{i}}+e_{t+1}^{a_{i}}\right)-C_{t}^{a_{i}}
$$

where $\Delta P_{t+1}^{a_{i}}$ - price change rate on $i$ asset at year $(t+1)$;

$e_{t+1}^{a_{i}}-$ interest rate on $i$ asset at year $(t+1)$;

$C_{t}^{a i}$ - transaction cost of $i$ asset sold at time $t$.

$$
C_{t}^{a i}= \begin{cases}a_{t}^{i}\left(\lambda_{t}^{a i}+\bar{\lambda}_{t, n}^{a i}\right) \cdot c_{t}^{a i} & \text { if } \lambda_{t}^{a i}+\bar{\lambda}_{t, n}^{a i}<0, \\ 0 & \text { if } \lambda_{t}^{a i}+\bar{\lambda}_{t, n}^{a i} \geq 0,\end{cases}
$$

where

$C_{t}^{a i}$ - transaction cost rate per unit of asset sold;

$l_{t+1}^{j}-$ amount of $j$ liability at time $(t+1)$;

$$
l_{t+1}^{j}=l_{t}^{j}\left(1+l_{t}^{l_{j}}+\overline{\lambda_{t, n}^{l_{j}}}\right)
$$

$\Delta t_{t+1}^{l_{j}}$ - amount of expenditure on $j$ liability in $(t+1)$ year. These expenditures consist of debt service on $j$ liability in $(t+1)$ year plus transaction cost $C_{t}^{l_{j}}$ of $j$ liabilities sold (changed) at the moment.

$$
\begin{gathered}
\Delta_{t+1}^{l j}=1_{\mathrm{t}}^{\mathrm{j}}\left(1+l_{t}^{j}+\overline{\lambda_{\mathrm{t}, \mathrm{n}}^{l_{j}}}\right) \times O_{t+1}^{l j}+C_{t+1}^{l j}, \\
C_{t}^{l j}= \begin{cases}l_{t}^{j}\left(\lambda_{t}^{l j}+\overline{\lambda_{t, n}^{l_{j}}}\right) \times C_{t+1}^{l j} & \text { if } \lambda_{t}^{l j}+\overline{\lambda_{t, n}^{l_{j}}}<0, \\
0 & \text { if } \lambda_{t}^{l j}+\overline{\lambda_{t, n}^{l_{j}}} \geq 0,\end{cases}
\end{gathered}
$$

where

$O_{t+1}^{l j}$ - payment rate per unit of liability $j$,

$C_{t+1}^{l j}-$ transaction rate per unit of $\mathrm{j}$ liability sold at $t$.
$\Delta_{t+1}^{\text {net }}$ - increase in total net amount of wealth in year $(t+1)$,

$$
\Delta_{t+1}^{n e t}=\left(\sum_{i} \Delta_{t+1}^{a i}-\sum_{j} \Delta_{t+1}^{l j}\right) .
$$

Now lets define inputs and identities of the IALP: $d_{t+1, p}^{a i}-$ probability distribution function of $i$ asset price index at the moment $(t+1)$.

$d_{t+1, e}^{a i}-$ probability distribution function of interest rate on asset $i$ in year $(t+1)$.

$d_{t+1, o}^{l j}-$ probability distribution function of payment rate on $j$ liability in year $(t+1)$.

$l_{t+1}$-growth rate of assets and liabilities in year $(t+1)$. $\sum_{i} a_{t}^{i}=\sum_{j} l_{t}^{j}-$ the main identities the beginning and at the end of each time interval.

Management mechanisms of IALP:

$U_{t+1}\left(\Delta_{t+1}^{\text {net }}\{S\}\right)$ utility function defining subject utility from amount of net wealth generated by exploitation of all assets and liability's.

$\{\mathrm{S}\}-$ symbolise stochasticity of $\Delta_{t+1}^{n e t}$.

Strategy

$$
U_{t+1}^{\Delta_{t+1} \times l_{t+1}}\left(\sum_{i} \Delta_{t+1, w}^{a i}-\sum_{j} \Delta_{t+1}^{l j}\right) \Rightarrow \text { optimum. }
$$

Optimum means maximum utility from chosen possibility taking into account guarantee of this possibility.

The main statistical relations between egzogenic variables would limit the analysis of the given situation. First, we will consider the existing statistical relations between interest rates earned by different categories of wealth and payments made at different liabilities, norms, which can be shown as correlation matrix C (A,L):

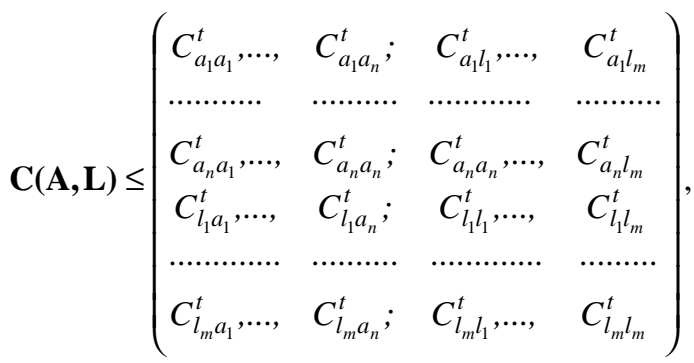

$\mathrm{C}_{a_{i} l_{j}}^{t}$ - is the correlation coefficient in year $t$ between 
$a$ category of wealth interest rate and payments according $j$ category of liabilities norms.

We will also consider the existing statistical relations between price increase indexes of different wealth categories in year $(t+1)$, that can be shown as correlation matrix $\mathbf{C}(\mathbf{P})$ :

$$
\mathbf{C}(\mathbf{P})=\left(\begin{array}{ccc}
C_{p^{a_{1}} p^{a_{2}}} & \ldots ., & C_{p^{a_{1}} p^{a_{n}}} \\
\ldots . . & \ldots . . & \ldots . . \\
C_{p^{a_{n}} p^{a_{1}}} & \ldots . . & C_{p^{a_{n}} p^{a_{n}}}
\end{array}\right)
$$

\subsection{The case}

Suppose that at time $t$ investment fund possess $€ 100 \mathrm{~m}$ allocated between three groups of assets as following: $€ 45 \mathrm{~m}$ in " 1 " asset, $€ 20 \mathrm{~m}$ in " 2 " asset, $€ 35 \mathrm{~m}$ in " 3 " asset. On the liability side there is following distribution: on " 1 " liability $-€ 55 \mathrm{~m}$, on " 2 " liability $-€ 30 \mathrm{~m}$, on " 3 " liability - €15m. Equity capital is among declared liabilities [7].

Macroeconomic and marketing analysis allows us make an assumption that the distribution of price increase possibilities of different assets categories will be such:

$$
\begin{gathered}
d_{t+1, p}^{a_{1}}-\mathrm{N}(0,9 ; 0,1), \quad d_{t+1, p}^{a_{2}}-\mathrm{N}(1,1 ; 0,2), \\
d_{t+1, p}^{a_{3}}-\mathrm{N}(1,1 ; 0,2) .
\end{gathered}
$$

The distribution of probability of interest rate possibilities in year $(\mathrm{t}+1)$ would be:

$$
\begin{gathered}
d_{t+1, e}^{a_{1}}-\mathrm{N}(0,15 ; 0,04), d_{t+1, e}^{a_{2}}-\mathrm{N}(0,20 ; 0,02), \\
d_{t+1, e}^{a_{3}}-\mathrm{N}(0,08 ; 0,02) .
\end{gathered}
$$

Adequately, the distribution of probability of liabilities payments norm would be:

$$
\begin{gathered}
d_{t+1, o}^{l_{1}}-\mathrm{N}(0,04 ; 0,01), d_{t+1, o}^{l_{2}}-\mathrm{N}(0,07 ; 0,02), \\
d_{t+1, o}^{l_{3}}-\mathrm{N}(0,05 ; 0,01) .
\end{gathered}
$$

At that time the statistical relations between different variables would look like this:

$$
\mathbf{C}(\mathbf{A} ; \mathbf{L})=\left(\begin{array}{cccccc}
1 & 0.05 & -0,1 & 0 & 0.15 & 0 \\
& 1 & 0,07 & 0.05 & 0 & 0.12 \\
& & 1 & 0 & 0.1 & 0 \\
& & & 1 & -0.05 & 0.15 \\
& & & & 1 & 0.2 \\
& & & & & 1
\end{array}\right),
$$

$$
\mathbf{C}(\mathbf{P})=\left(\begin{array}{ccc}
1 & 0.1 & 0 \\
& 1 & -0.2 \\
& & 1
\end{array}\right) .
$$

Strategic investment fund's goals on given stage are: amount existing assets to $€ 110 \mathrm{~m}$ by increasing existing liabilities and rebalancing existing structure of assets and liabilities in order to optimise the growth of net wealth in time period $[\mathrm{t},(\mathrm{t}+1)]$.

Analytically the problem could be formulated in such a manner: define fractions of newly invested assets in $i$ category of asset $\bar{\lambda}_{t, n}^{a_{i}}$ and growth index of $i$ asset in result of rebalancing existing up to the time $t$ assets $I_{t+1}^{a_{i}}$ and fractions of newly borrowed liabilities in liability $j$ category $\bar{\lambda}_{t, n}^{l_{j}}$ and growth index of $j$ liability in result of rebalancing existing up to the time liabilities $-I_{t+1}^{l_{j}} \quad(i=1,2,3,4 ; j=1,2,3,4)$ in order to optimise subject utility from the growth of net wealth.

Price indes $\left(p_{t+1}^{a_{i}}\right)$, interest rate $\left(e_{t+1}^{a_{i}}\right)$ on $i$ asset, payment rate per unit of liability $j-o_{t+1}^{l_{j}}$ are stochastic variables, so the problem of net wealth increase utility optimisation is the identical case of IALP and could be solved by the same techniques as classical (modern) investment portfolio or as adequate to the stochasticity of assets and liabilities portfolio [15].

\subsection{Interpretation of the obtained results}

Using imitation technologies we can define wealth increase possibilities of year $(t+1)$ shown in the figures bellow.

The aim of the investor is to choose an optimal portfolio, i.e. the best according its investment characteristics. The criteria for choosing the optimal portfolio have to be based on the main investment characteristics: average portfolio profitability and risk, which is determined as a dispersion or standard deviation [11]. An investor follows only evaluation of the profitability and risk of a portfolio when selecting, and that's why the criteria set is very important to investor. Usually, all possible assets (or liabilities) portfolio image sets are called criteria sets. Analysing integrated assets and liabilities portfolio, first of all, separate assets and liabilities portfolio sets are determined; their images depend on the specifics of investment fund activity. According to strategic fund's goal, mentioned 
above, assets portfolio set expresses the increase possibilities of all net assets of all categories of wealth. Portfolios with images on criteria set limit are very important for the investment fund. Two criteria complicate the selection of an optimal portfolio, since improving one criterion often worsens the other.

The portfolio is called effective, if there is no better portfolio according to one of these criteria. Efficiency characteristics can be analysed graphically. Images of effective portfolios belong to the edge of the criteria set. Effective portfolios from possible portfolios' sets form the effective line of this set, and their whole complex forms the effective zones of a criteria set (see fig. 3, 4). Effective lines serve as isoguarantees in this case.

We can see isoguarantee of minimum $(0,001)$, isoguarantee of maximum $(0,995)$, isoguaranties of mean and I, II, III quartiles. Note that values of isoguaranties are almost entirely increasing as the dispersion increases, so some remarks can be made:

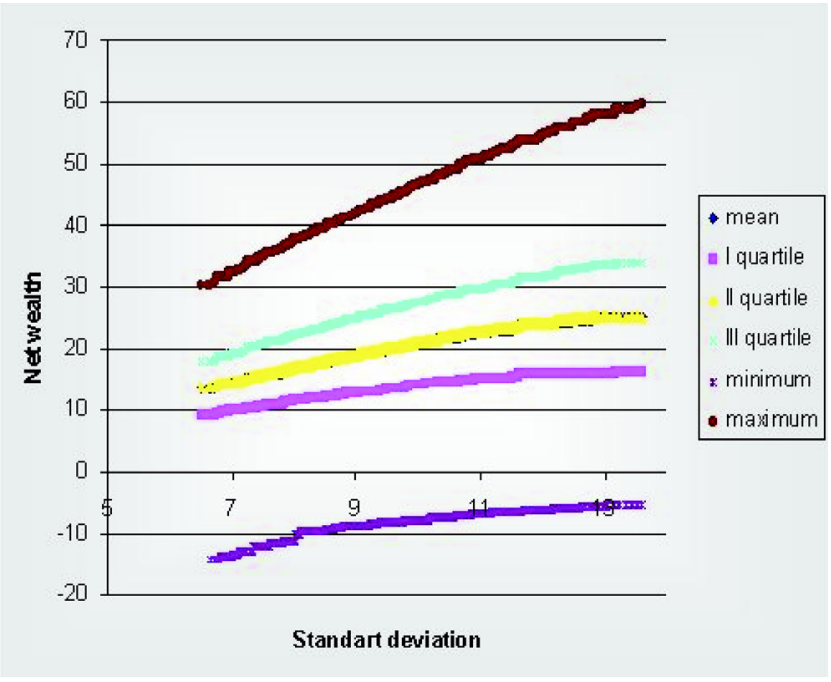

Fig. 3. Assets portfolio efficiency zone

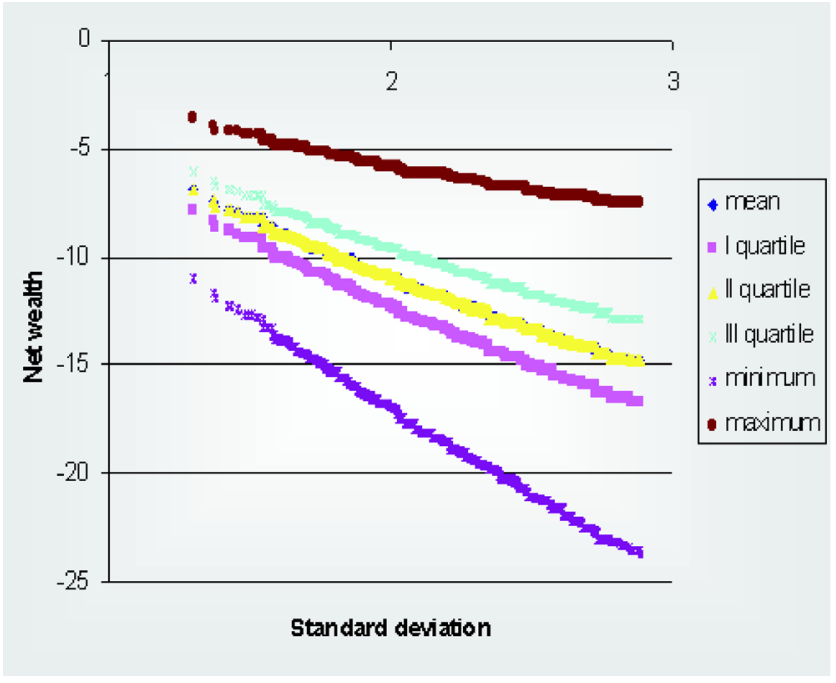

Fig. 4. Liabilities portfolio efficiency zone
First, isoguarantee gives us information that with chosen guarantee the increase of net assets will be no smaller than the value of isoguarantee at a given level of risk, if you are not choosing from the set of possibilities, but from the effective lines only.

Second, the third coordinate is necessary if we seek for better understanding and disclosing the possibilities of net asset increase. In the figures of spatial views the risk is put on abscissa axis, increase of assets on ordinate, and level of guaranties on applicate. Spatial views of survival functions family give information about the assets possibilities, which are chosen below the level of isoguarantee (see fig. 5, 6). This explains why the higher level of net assets, when guarantee is the same, not necessarily means higher expected utility. Besides, trying to find the best structure of assets and liabilities, there were limited variation possibilities for causing variables, in other way it would had also required changing $\mathrm{c}_{t}^{a_{i}}$ coefficients parallelly.

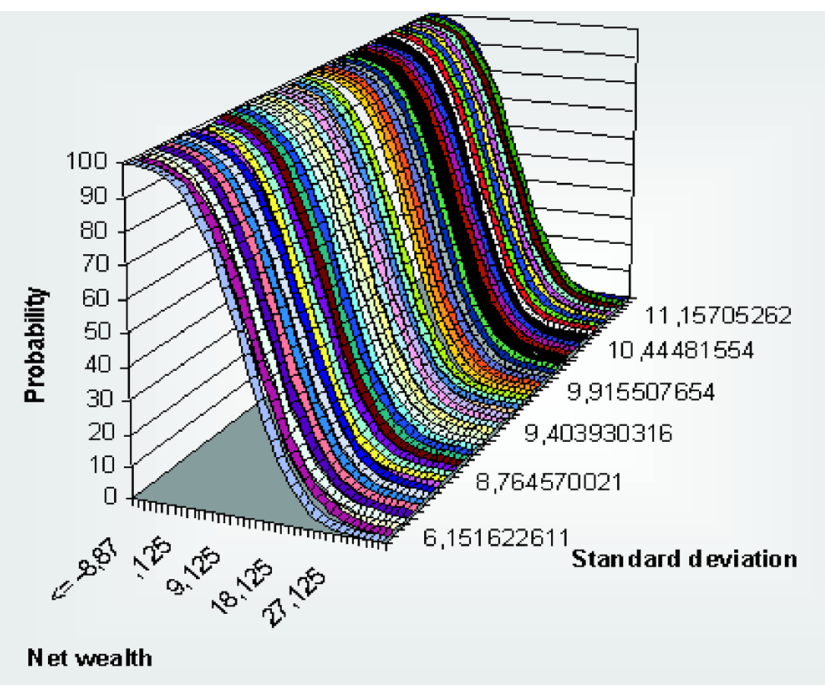

Fig. 5. Assets portfolio survival function

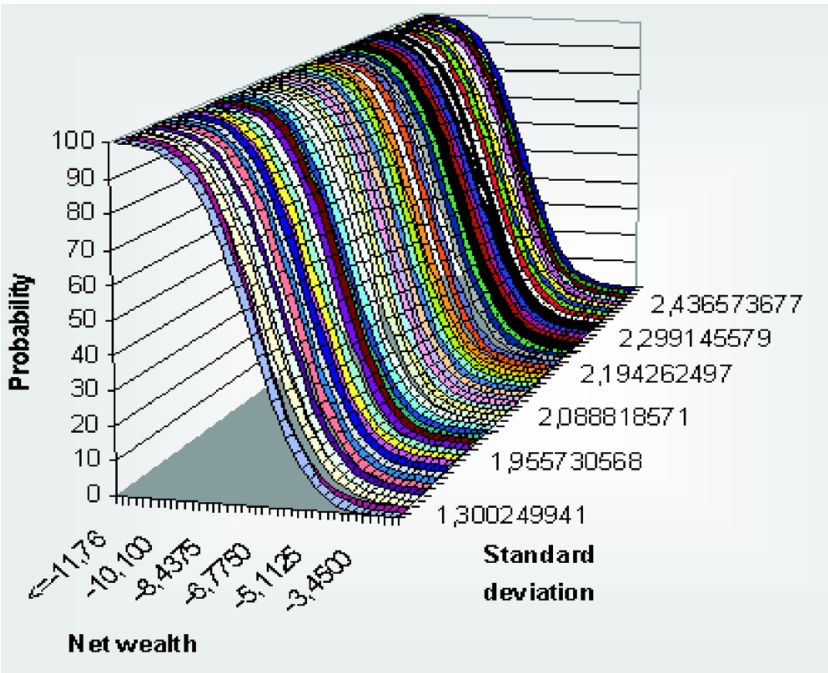

Fig. 6. Liabilities portfolio survival function 
The task of the manager of an integrated portfolio of assets and liabilities is to choose such a portfolio that will optimise the investment and debt structure according to chosen criteria. Optimisation criteria should be based upon the maximisation of the portfolio's usefulness, according to the distribution of profitability possibilities in the integrated portfolio of assets and liabilities and indicator of this distribution - risk, which reflects profitability possibilities distribution.

An integrated portfolio takes one or other geometric shape because it is formed from a peculiar composition of assets portfolio and liabilities portfolio. The figures give information about net assets increase possibilities in year $(\mathrm{t}+1)$. A study of an integrated portfolio of assets and liabilities of investment fund is analysis that could probably provide one with a chance of interpreting in a new way or even supplement classical portfolio results. Some peculiarities of an integrated portfolio of an investment fund are revealed when comparing it with classical investment portfo-

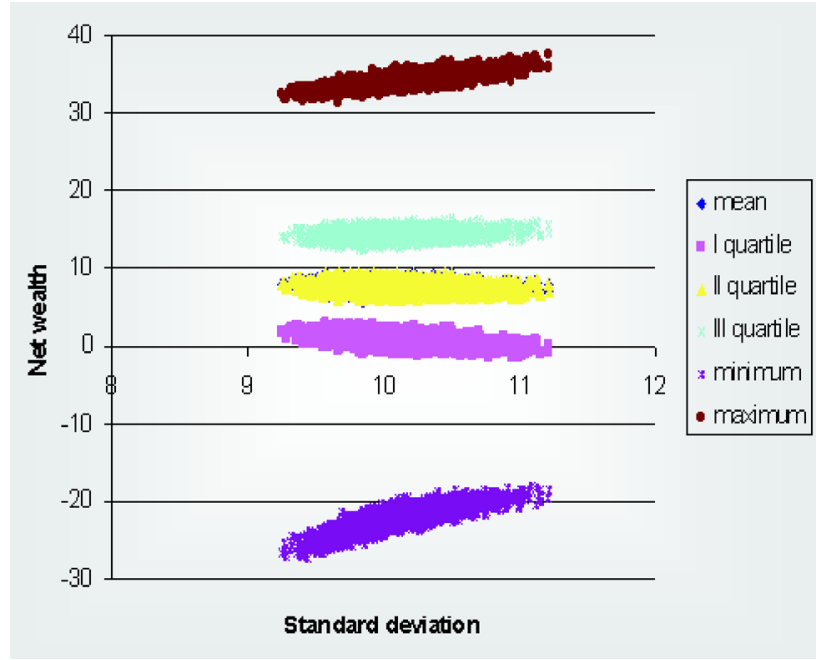

Fig. 7. Integrated portfolio set

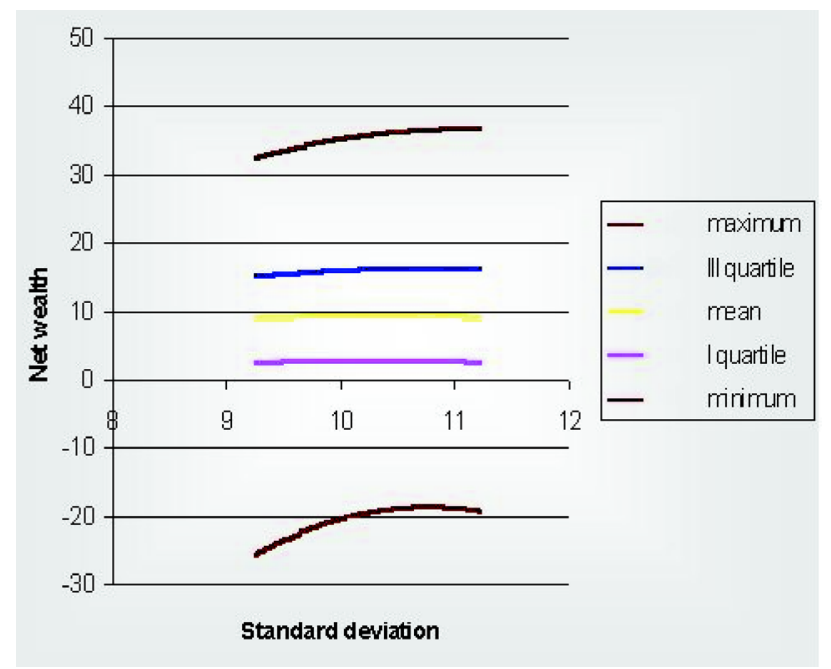

Fig. 8. Integrated portfolio efficiency zone lio. Apexes of a possible portfolio set in a classical portfolio match with the basic investment coordinates - standard deviation and mean. Integrated portfolio apexes, for example, if portfolio is described using standard deviation and mean interaction, match with coordinates of the sum of assets and liabilities pairs. Integrated portfolio set can be observed in figure 7 . The efficiency zone of integrated portfolio (see fig. 8), as well as the efficiency zones of assets and liabilities portfolios separately, shows an entire complex of efficiency lines, describing minimal and maximal efficiency limits. It gives information about utility dynamics possibilities in changing risk levels.

Density function (see fig. 9) discloses what probability guarantees certain profitability at the chosen level of risk or chosen profitability at the certain level of risk. Survival function (see fig. 10) gives relevant information about net assets increase possibilities and shows what probability guarantees profitability not smaller than chosen one at the certain level of risk.

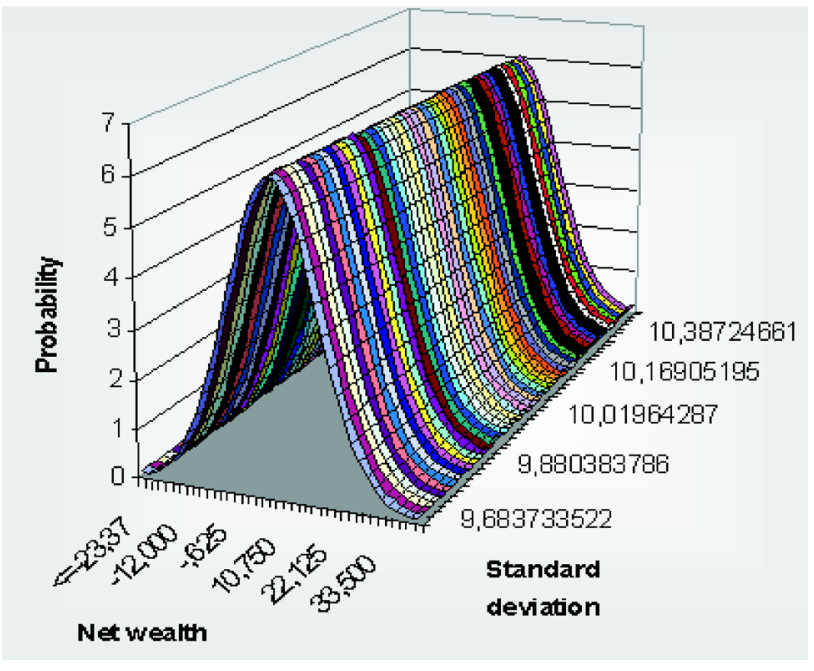

Fig. 9. Density function of integrated portfolio

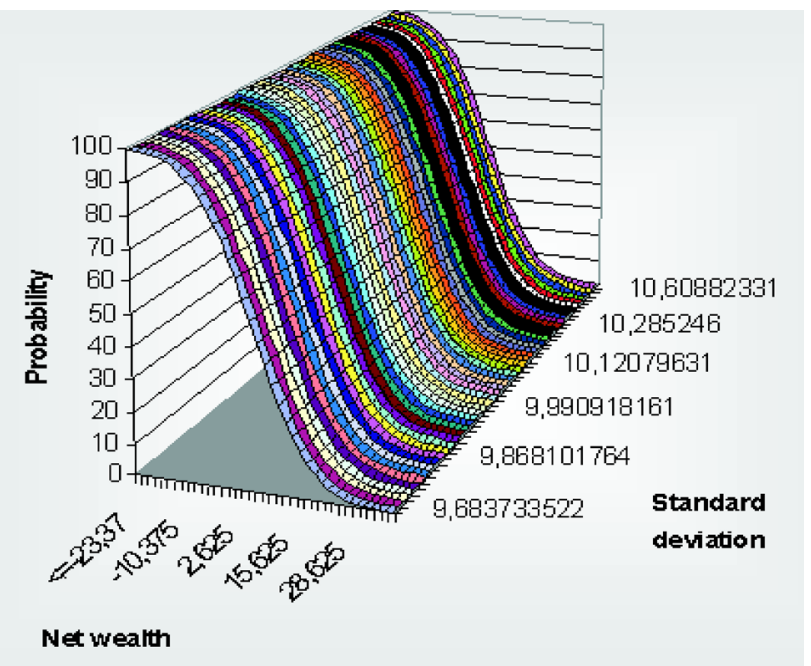

Fig. 10. Survival function of integrated portfolio 


\section{Conclusions}

The basis of economic development and one of the most important factors conditioning the growth of the standard of living is an efficiently operating finance system. That is why it is important to improve the activity of the finance system, while expanding the network of financial institutions as well as the activity of one of the largest financial intermediaries - an investment fund. An active role played by non-banking financial intermediaries in a financial system is an indication of its maturity.

Over the past decade, investment funds have gone from strength to strength, developing from a niche product into one of the most popular savings products on the market today. Investment funds are now considered by many individual investors as an attractive alternative to other financial assets. The advantages that they offer in terms of diversification, liquidity, costs, and real returns contribute to explain their success as saving instruments. Investment funds have even greater importance in the countries of growing economy, where they contribute to harmonising and balancing the national securities market, guaranteeing liquidity, inducing saving and slowing down consumption.

Taking into account the increasing influence of risk and uncertainty upon the results of investment activity and the increasing means for risk management, reports and other information should be organised according to pragmatic guidelines in order to facilitate the most reasonable decisions.

The specific objective of investment fund is the management of the general efficiency of assets and liabilities, which requires the means for making decisions about the integration of profitability and risk. Integrated assets and liabilities portfolio helps to reinforce integrated assets and liabilities management system as strategic decision making system. It becomes widely used instrument in the financial system and can help answer the main questions for investment funds, what strategy to choose, how to form and manage the securities portfolio.

\section{References}

1. Basso A., Funari S. A data envelopment analysis approach to measure the mutual fund performance. Euro- pean Journal of Operational Research, 135, 2001, p. 477-492.

2. Boender G. C. E. A hybrid simulation/optimisation scenario model for asset/liability management. European Journal of Operational Research, 99, 1997, p. 126-135.

3. Eng M. V., Lees F. A., Mauer L. J. Global finance, Harper Collins College Publishers, 1995, 768 p.

4. Fabodzzi F. J. Investment management, 2nd ed., Prentice Hall, Englewood Cliffs, 1999, 837 p.

5. Fleten S. E., Huyland K., Wallace S. W. The performance of stochastic dynamic and mixed portfolio models. European Journal of Operational Research, 140, 2002, p. 37-49.

6. Holmer M. Integrated asset-liability management: an implementation case study, in: Ziemba W. T., Mulvey J. M. (Eds.), Worldwide Asset and Liability Modelling, Publication of Newton Institute, Cambridge University Press, 2001, p. 581-608.

7. International statistical release, Worldwide investment fund assets and flows, third quarter 2002. 13 p.

8. Kouwenberg R. Scenario generation and stochastic programming models for asset liability management. European Journal of Operational Research, 134, 2001, p. 279-292.

9. Kusy M. I., Ziemba W. T. A bank asset and liability model. Operations Research, 34, 1986, p. 359-376.

10. Mansini R., Speranza M. G. Heuristic algorithms for the portfolio selection problem with minimum transaction lots, European Journal of Operational Research, 114, 1999, p. 219-233.

11. Markowitz H. M. Portfolio selection. Journal of Finance, 7, 1952, p. 71-91.

12. Murthi B.P.S., Choi Y. K., Desai P. Efficiency of mutual funds and portfolio performance measurement: A non-parametric approach. European Journal of Operational Research, 98, 1997, p. 408-418.

13. Pelsser A., Vorst T. Transaction costs and efficiency of portfolio strategies. European Journal of Operational Research, 91, 1996, p. 250-263.

14. Pozen R. C., The Mutual Fund Business, 1998, 744 p.

15. Rutkauskas A. V. Formation of Adequate Investment Portfolio for Stochastically Possibilities, Property Management, Volume 4, No. 2, Vilnius, Technika, 2000, p. 100-116.

16. Sharpe W. F., Alexander G. J., Bailey J. V., Investments, 6th ed., Prentice Hall International, Inc., 1999.

17. Sharpe W.F. Asset allocation: Management style and performance measurement. Journal of Portfolio management 18, p. 7-19. 